\title{
Approach to estimating the maximum depth for glacially induced hydraulic jacking in fractured crystalline rock at Forsmark, Sweden
}

\author{
M. Lönnqvist ${ }^{1,2}$ and H. Hökmark ${ }^{1}$ \\ Received 21 December 2012; revised 27 June 2013; accepted 9 July 2013; published 12 September 2013.
}

[1] Hydraulic jacking is a significant dilation of a fracture that occurs when the pore pressure within it exceeds the sum of the fracture's normal stress and tensile strength. This phenomenon may occur during a glacial period because of changes in hydraulic and mechanical boundary conditions. Since hydraulic jacking may alter flow patterns and the transport capacity of the rock mass, its possible effects on the long-term performance of a nuclear waste repository should be considered. We develop an approach to assess glacially induced hydraulic jacking in fractured crystalline rock and establish bounding estimates of the maximum jacking depth for the Swedish Nuclear Fuel and Waste Management Company's (SKB) repository site at Forsmark. The pore pressure is estimated using mechanically uncoupled two-dimensional poroelastic continuum models with hydraulic and mechanical conditions based on SKB's reconstruction of the Weichselian glaciation at this site (120-0 ka B.P.). For warm-based conditions, the water pressure at the ice/bed interface is set at $98 \%$ of the mechanical load, whereas for glacial conditions with extensive proglacial permafrost, the corresponding water pressure is set at a (lower) annual average value. We demonstrate that the pore pressure within the uppermost kilometer of rock is mainly governed by the water pressure at the ice/bed interface and that the mechanical impact of the ice load on the pore pressure is sufficiently small to be ignored. Given the current and estimated future stress conditions at Forsmark, hydraulic jacking is mainly of concern for subhorizontal fractures, i.e., it is sufficient to consider situations when the pore pressure exceeds the vertical stress. We conclude that hydraulic jacking at Forsmark will be confined to the uppermost $200 \mathrm{~m}$ of the rock mass.

Citation: Lönnqvist, M., and H. Hökmark (2013), Approach to estimating the maximum depth for glacially induced hydraulic jacking in fractured crystalline rock at Forsmark, Sweden, J. Geophys. Res. Earth Surf., 118, 1777-1791, doi:10.1002/jgrf.20106.

\section{Introduction}

[2] During a glacial period, high pore pressures are expected to build up within the rock mass because of elevated water pressures at the ice/bed interface and because of changes in mechanical load. Such changes may affect both the transport capacity of the rock mass and the stability of individual fractures and fracture zones [e.g., Fälth et al., 2010; Hökmark et al., 2010; Lagerbäck and Sundh, 2008]. Hydraulic jacking of a fracture occurs when the pore pressure within it exceeds the sum of the fracture's normal stress and tensile strength. As a result, the fracture will dilate and its transmissivity will increase. If the dilatancy is significant, the stress concentrations around the tips of the fracture may be sufficient for the fracture to propagate; a process known as hydraulic fracturing or hydrofracking.

\footnotetext{
${ }^{1}$ Clay Technology AB, Lund, Sweden.

${ }^{2}$ Division of GeoEngineering, Department of Civil and Environmental Engineering, Chalmers University of Technology, Gothenburg, Sweden.

Corresponding author: M. Lönnqvist, Clay Technology AB, IDEON Science Park, SE-223 70 Lund, Sweden. (ml@claytech.se)

(C)2013. American Geophysical Union. All Rights Reserved. 2169-9003/13/10.1002/jgrf.20106
}

[3] In rocks with a relatively flat surface topography, subhorizontal fractures are typically in uniform and modest compression over large areas and may propagate large distances as long as the driving (jacking) pore pressure is maintained. Propagation may, therefore, continue until it is arrested at an intersecting discontinuity that can open or slide, or if the fracture propagates into stiffer or more incompressible rock [Pollard and Aydin, 1988]. For subvertical fractures subjected to a stress field typical of the Fennoscandian shield, the normal stress will exceed the fluid pressure at some depth below which the propagation will be suppressed and eventually die out. However, it is beyond the scope of this paper to attempt to determine how far below that level the propagation actually would penetrate in case it is not arrested. The effects on the hydraulic conditions of any pore pressure induced dilation of newly created as well as existing fractures is assumed here to be, relatively seen, modest as long as the fluid pressure does not exceed the normal stress, i.e., as long as jacking does not occur. Therefore, the occurrence of pore pressure induced tensile effective stress is taken to determine the maximum jacking depth. Since hydraulic jacking will change flow patterns and the transport capacity of the rock mass significantly, 
it may, if it occurs at large enough depths, have implications for the long-term performance of the repository for deep geological disposal of high-level nuclear waste planned to be excavated at a depth of approximately $450 \mathrm{~m}$ in the Forsmark area, Sweden, by the Swedish Nuclear Fuel and Waste Management Company [2011].

[4] At the Forsmark site, sediment-filled gently dipping fractures with very large apertures (greater than $0.5 \mathrm{~m}$ ) have been observed down to depths of a few tens of meters [Swedish Nuclear Fuel and Waste Management Company (SKB), 2005]. One explanation [e.g., Hökmark et al., 2006; Pusch et al., 1990] is that these fractures were dilated by hydraulic jacking events during a previous glacial period and that the sediment has preserved the large apertures. Although these observations were only made in the near-surface parts of the bedrock, it is theoretically possible for hydraulic jacking to be initiated at significantly larger depths. Talbot [1990, 1999] suggested that pressurized water beneath an ice sheet similar to the Weichselian ice sheet could be sufficient to lift rock blocks with thicknesses up to $1000 \mathrm{~m}$.

[5] Over the years, several studies have been conducted on hydraulic jacking occurring during a glacial cycle, e.g., Bench Mark Test 3 of the international DECOVALEX (Development of Coupled Models and Their Validation Against Experiments) III project [Boulton et al., 2004; Chan and Stanchell, 2005; Chan et al., 2004, 2005; Vidstrand et al., 2008]. The DECOVALEX project was aimed at improving the understanding of coupled processes in the geosphere that could affect the long-term mechanical stability and groundwater flow in a rock mass containing a nuclear waste repository. Even though hydraulic jacking was not predicted at the repository depth $(500 \mathrm{~m})$ [Chan and Stanchell, 2005; Chan et al., 2004, 2005], a significant reduction in the effective vertical stress was observed during glacial retreat [Chan and Stanchell, 2005; Chan et al., 2005]. It was suggested that the cause of the reduction in effective stress was due to high pore pressures being retained by the low-permeable rock whereas the vertical stress would return to its initial state directly after the deglaciation. Chan et al. [2005] did not exclude the possibility that jacking could occur at large depths, under certain circumstances, during deglaciation. However, Boulton et al. [2004] concluded that "hydraulic jacking at depth is unlikely to be important." In the modeling work by Vidstrand et al. [2008], tensile effective stresses were observed at depths of $500 \mathrm{~m}$, but these could be attributed to not accounting for crustal bending, i.e., flexural stresses, in the models. On the basis of the results and observations described above, it is not possible to draw any general conclusions regarding the potential for hydraulic jacking at depths larger than a few tens of meters during a glacial cycle. Site-specific hydrogeological conditions, the state of stress and ice sheet models appear to play a significant role in determining the maximum jacking depth.

[6] This paper presents an approach to estimate the maximum depth for hydraulic jacking during a glacial cycle at the site selected by SKB for the Swedish repository for spent nuclear fuel, based on a two-dimensional, poroelastic continuum approximation of the rock mass. The influence of mechanical loading and unloading on the pore pressure evolution is assessed and maximum jacking depths that potentially could be expected during different phases of a glacial cycle are established.
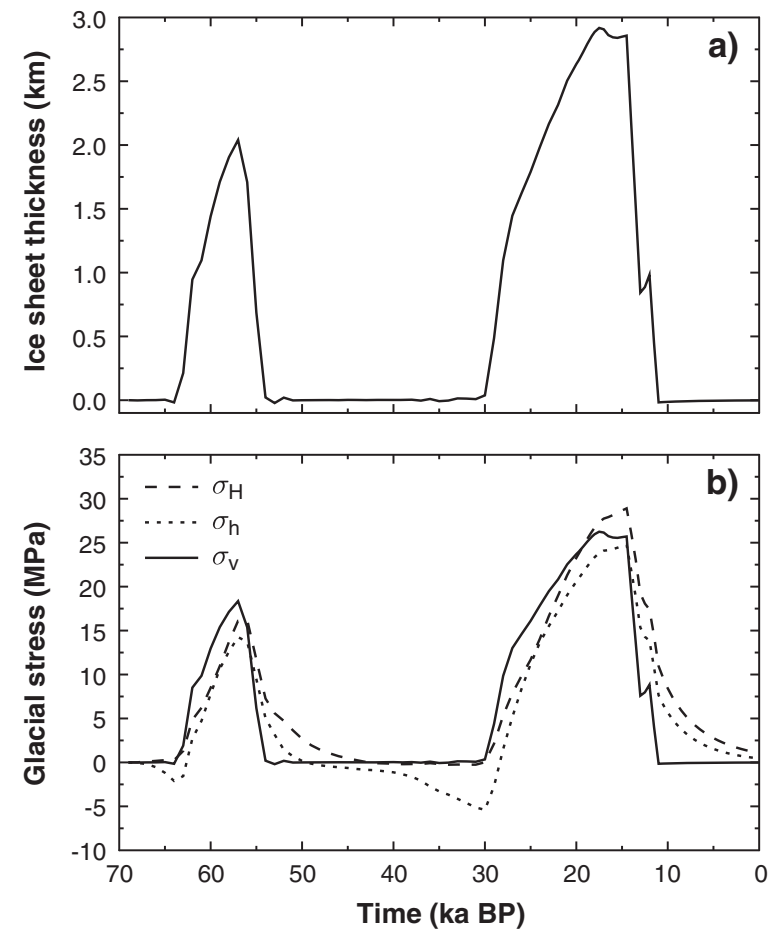

Figure 1. (a) Näslund's [Swedish Nuclear Fuel and Waste Management Company (SKB), 2006] model of the Weichselian ice sheet thickness at the Forsmark site. (b) Corresponding glacial stress evolution at $500 \mathrm{~m}$ depth in the rock obtained from coupled ice/crust/mantle simulations by Lund et al. [2009].

\section{Aspects on Glacially Induced Jacking Relevant for the Forsmark Site}

\subsection{SKB's Reference Glacial Scenario}

[7] SKB's reference glacial scenario is [Swedish Nuclear Fuel and Waste Management Company (SKB), 2010a, p. 12] "one example of a conceivable future evolution that covers climate-related conditions and sequences that could be expected in a $100 \mathrm{kyr}$ time perspective" and is therefore not a prediction of future conditions at the Forsmark site. The glacial scenario has been exemplified using a model reconstruction [see Swedish Nuclear Fuel and Waste Management Company (SKB), 2010b, section 3.22, and references therein] of the latest major glaciation in Scandinavia, the Weichselian (120-0 ka before present (B.P.)), during which the Forsmark site experienced two major glacial advances and retreats as shown in Figure 1a. In the reference scenario, i.e., repetition of the Weichselian glaciation, the first glacial advance during the next glacial period will occur about $60 \mathrm{ka}$ after present (A.P.) and the second glacial advance about 90 ka A.P. [SKB, 2010a]. In the present analyses, the start of the glacial period is arbitrarily chosen to coincide with the time when the mechanical effects of the approaching ice sheet first become noticeable at about 69 ka B.P. [cf. Hökmark et al., 2010; Lund et al., 2009].

\subsection{Potential for Hydraulic Jacking}

[8] A continental-scale ice sheet, such as the Weichselian ice sheet, will cause the Earth's crust to bend and induce 
flexural stresses in the upper part of the crust. The present understanding of the stress evolution at the Forsmark site [Lund et al., 2009] is that, with the exception of the time period leading up to a glaciation when forebulge flexure tends to reduce the horizontal stresses, the glacially induced horizontal stresses will be of approximately the same magnitude as, or be greater than, the vertical stress (Figure 1b). Since the present-day horizontal stresses at the Forsmark site are significantly greater than the vertical stress [Glamheden et al., 2007a] and sufficiently high to balance the stress reduction associated with the forebulge [Hökmark et al., 2010; Lund et al., 2009], it appears that the vertical stress will be the minor principal stress and that hydraulic jacking consequently will primarily be initiated in subhorizontal fractures. Therefore, the assessment of the potential for hydraulic jacking at the Forsmark site is essentially a question of comparing the magnitude of the pore pressure with that of the vertical stress.

[9] While the vertical stress can be approximated well by the sum of the rock overburden and the local ice load at all positions and at all times, the pore pressure evolution is intricately linked to all aspects of the evolution of the ice cover: the history of the water pressure at the ice/bed interface, the rock permeability at different depths, hydromechanical couplings etc. Since the water pressure at the ice/bed interface is unlikely to be sustained at levels exceeding the overburden pressure, systematic occurrences of hydraulic jacking at large depths below the main ice cover are judged unlikely. Stress disturbances in the rock below major subglacial tunnels are judged to have a limited range (cf. Kirsch solutions for circular excavations in rock [e.g., Brady and Brown, 1993] for approximate estimates). Therefore, any associated hydraulic jacking will be limited to the nearsurface parts of the rock. For hydraulic jacking to be initiated at any significant depth beneath the main cover of the ice sheet, the ice front needs to be stationary covering bedrock with large areas of poor drainage: a situation schematically shown in Figure 2a. One type of realization would be long, highly transmissive fractures transferring high pore pressures from far under the ice to positions where the vertical stress is sufficiently low to initiate hydraulic jacking at some depth. However, the restrictions that need to be put on fracture lengths and connectivity are judged to be unrealistic. Although the simplistic calculation of the maximum jacking depths shown in Figure 2a does not account for the transient evolution of the pore pressure, it shows that the potential for hydraulic jacking will be maximized in the rock beneath the ice margin where the vertical stress is low but where the pore pressure can be comparatively high. In particular, this is likely to be the case beneath an advancing ice front with extensive proglacial permafrost (Figure 2b). If permafrost conditions also prevail during a deglaciation and prevent drainage of high pore pressures behind the retreating ice front [cf., e.g., Pusch et al., 1990; Lagerbäck and Sundh, 2008], there is potential for hydraulic jacking at very large depths. However, in the reference deglaciation scenario for Forsmark [SKB, 2010a], the ice sheet is warm-based, i.e., there is liquid water at the ice/bed interface, and the site is submerged. Also in this latter case, a significant proportion of the glacially induced pore pressure may be retained by the rock. Hydraulic jacking may occur beneath the ice margin as the ice front retreats over the landscape (see Figure 2c).
The evolution of the ice sheet cover and Forsmark-specific hydrogeologic properties are described in later sections of the paper (see section 3), whereas possible implications of the hydromechanical couplings are discussed below.

\subsection{Influence of Mechanical Loading and Unloading}

[10] A rigorous quantitative assessment of hydraulic jacking during a glacial cycle would require that equations of fluid flow and stress (or deformations) are solved in a fully coupled fashion. Hydromechanical couplings affect the pore pressure in two ways.

[11] First, changes in stress and pore pressure may alter the permeability of the rock mass. In an assessment by Hökmark et al. [2010] for the Forsmark site, glacially induced variations in transmissivity of differently oriented fractures were typically in the range $50-200 \%$ of present-day values. Given that present-day transmissivity values span several orders of magnitude [Follin et al., 2007], these variations are likely to be of subordinate importance for the pore pressure evolution.

[12] Second, changes in mechanical loading will alter the available pore space and influence the pore pressure evolution. For the simplified case of one-dimensional vertical loading and unloading, a coupled model without account of flexural stresses would give an increase in pore pressure during glacial advance and a corresponding reduction during glacial retreat compared with an uncoupled model [see, e.g., Lemieux et al., 2008a]. Glacial loading and unloading involve, however, crustal bending and flexural stresses which depend not only on the vertical load but also on the elastic and viscous properties of the crust and the mantle. The flexural stresses do not change immediately in direct response to changes in the ice load. Therefore, a quantitative assessment of the mechanically induced disturbances of the pore pressure during a glacial cycle should be based on state-of-the-art ice/crust/mantle analyses, such as those conducted by Lund et al. [2009], that also capture the evolution of the flexural stresses (cf. Figure 1b). In this paper, we have adopted the sign convention in which compressive stresses are positive.

[13] For general three-dimensional loading conditions, the equation for isothermal fluid flow in a poroelastic continuum is written [Neuzil, 2003]

$$
\nabla \cdot\left(K_{H} \nabla p\right)=S_{S 3} \frac{\partial p}{\partial t}-\beta S_{S 3} \frac{\partial \sigma_{t}}{\partial t}
$$

where $p(\mathrm{~Pa})$ is the pore pressure in excess of hydrostatic pressure, $K_{H}(\mathrm{~m} / \mathrm{s})$ is the hydraulic conductivity, $S_{S 3}\left(\mathrm{~m}^{-1}\right)$ is the three-dimensional coefficient of specific storage, $\sigma_{t}$ $(\mathrm{Pa})$ is the change in mean total stress, and $\beta$ (dimensionless) is a three-dimensional loading coefficient (also known as Skempton's coefficient) that represents the change in fluid pressure to change in mean total stress under undrained conditions. Skempton's coefficient can be calculated from the elastic properties and porosity of the rock mass and the bulk modulus of water (see, e.g., Neuzil [2003] for details) and can, in theory, take on values between zero and one depending on the compressibility of the rock. Values quoted in the literature [Neuzil, 2012] range from about 0.2 for lowporosity rocks at very large depths to between 0.5 and 1 for rocks at shallower depths. 

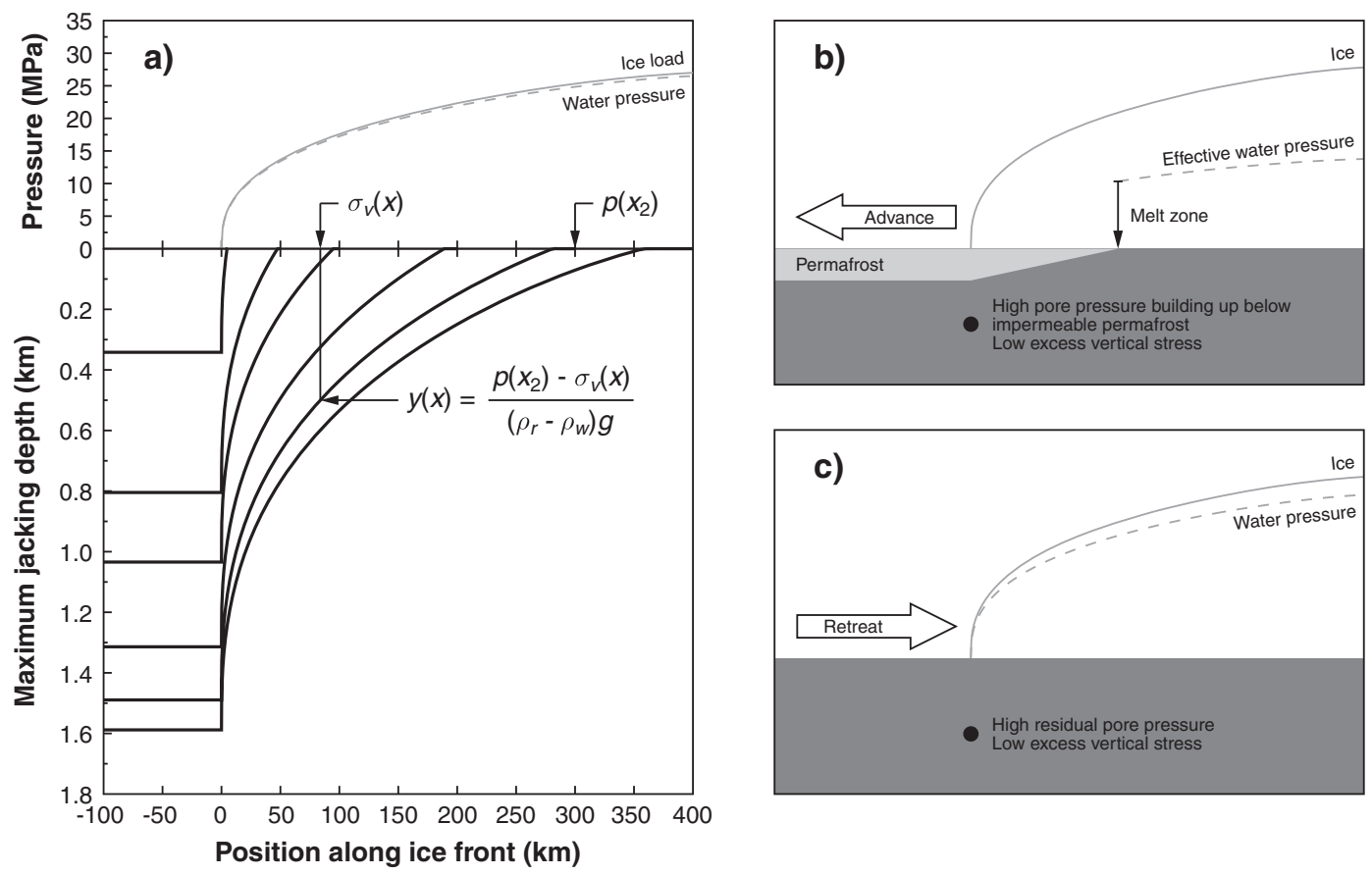

Figure 2. (a) Maximum jacking depth as function of distance $x$ to ice margin for horizontal fractures that are hydraulically connected to the pressurized ice/bed interface at position $x_{2}$ but perfectly isolated otherwise. (b) Principles of stress-pressure situation beneath an advancing ice front with extensive proglacial permafrost. (c) Stress-pressure situation beneath the front of a retreating warm-based ice sheet.

[14] By assuming that the glacially induced change in mean total stress does not vary spatially, which is a very good approximation of the conditions in the upper crust, cf. Lund et al. [2009], and that the hydraulic properties of the rock mass can be represented by a globally valid hydraulic diffusivity (i.e., ratio of hydraulic conductivity to coefficient of specific storage), we have solved the equation for fluid flow, equation (1), analytically in a one-dimensional semi-infinite continuum representation of the rock mass (see Appendix A, section A1 for derivation). For warm-based conditions, i.e., a situation when there is pressurized liquid water at the ice/bed interface, the change in pore pressure, as a function of depth $(y)$ and time $(t)$, is given by

$$
\begin{aligned}
p(y, t)= & \frac{2}{\sqrt{\pi}} \int_{y / \sqrt{4 \kappa t}}^{\infty}\left[p_{0}\left(t-\frac{y^{2}}{4 \kappa \eta^{2}}\right)\right. \\
& \left.-\beta \sigma_{t}\left(t-\frac{y^{2}}{4 \kappa \eta^{2}}\right)\right] \exp \left(-\eta^{2}\right) \mathrm{d} \eta+\beta \sigma_{t}(t),
\end{aligned}
$$

where $\kappa=K_{H} / S_{S 3}\left(\mathrm{~m}^{2} / \mathrm{s}\right)$ is the hydraulic diffusivity, $p_{0}(t)$ is the water pressure at the ice/bed interface $(y=0)$, and $\eta$ is the (dimensionless) integration variable.

[15] A qualitative assessment of the influence of temporal variations in stress on the pore pressure evolution is subsequently obtained by analyzing equation (2) for different values of Skempton's coefficient, $\beta$. Figure 3 shows the mechanically induced pore pressure obtained using the mean total stress $\left(\sigma_{t}=\left(\sigma_{H}+\sigma_{h}+\sigma_{v}\right) / 3\right)$ at $500 \mathrm{~m}$ depth in SKB's reference glacial cycle for Forsmark (Figure 1b) and the water pressure at the ice/bed interface set at zero.

[16] For values of the hydraulic diffusivity considered representative of the rock mass at Forsmark (between $1 \times$
$10^{-4} \mathrm{~m}^{2} / \mathrm{s}$ and $1 \times 10^{-1} \mathrm{~m}^{2} / \mathrm{s}$, cf. section 3.4$)$, the mechanical impact on the pore pressures at repository depth (approximately $500 \mathrm{~m}$ ) is small to modest (Figures $3 \mathrm{a}$ and $3 \mathrm{~d}$ ). This is also the case at larger depths if the hydraulic diffusivity is high (Figures $3 b$ and 3c). For low values of the hydraulic diffusivity, the impact of the mechanical load is demonstrated more clearly. As the ice margin passes over the site at, e.g., 39 and $58 \mathrm{ka}$ (Figures $3 \mathrm{e}$ and $3 \mathrm{f}$ ), an uncoupled analysis will result in a higher pore pressure. At very large depths, the pore pressure is dominated by the stress term $\beta \cdot \sigma_{t}(t)$.

\section{Modeling Approach}

\subsection{Governing Equations}

[17] The discussion in the preceding sections shows that although the mechanical effects of glacial loading and unloading perturb the pore pressure at all times and at all depths, its impact is sufficiently small to be ignored by comparison with the pore pressure governed by the pressurized water at the ice/bed interface. Thus, the equation for fluid flow (1) is simplified to a diffusion equation:

$$
\nabla^{2} p=\frac{1}{\kappa} \frac{\partial p}{\partial t}
$$

Although fluid flow in fractured crystalline rocks, such as at the Forsmark site, mainly takes place within the fracture network, a continuum representation of the rock mass can be justified since the flow during a glacial cycle is considered on a scale much larger than the length of the dominating fractures [e.g., Swedish Nuclear Fuel and Waste Management Company (SKB), 2010c]. At the Forsmark site, there does not appear to be any very large isolated fractures 

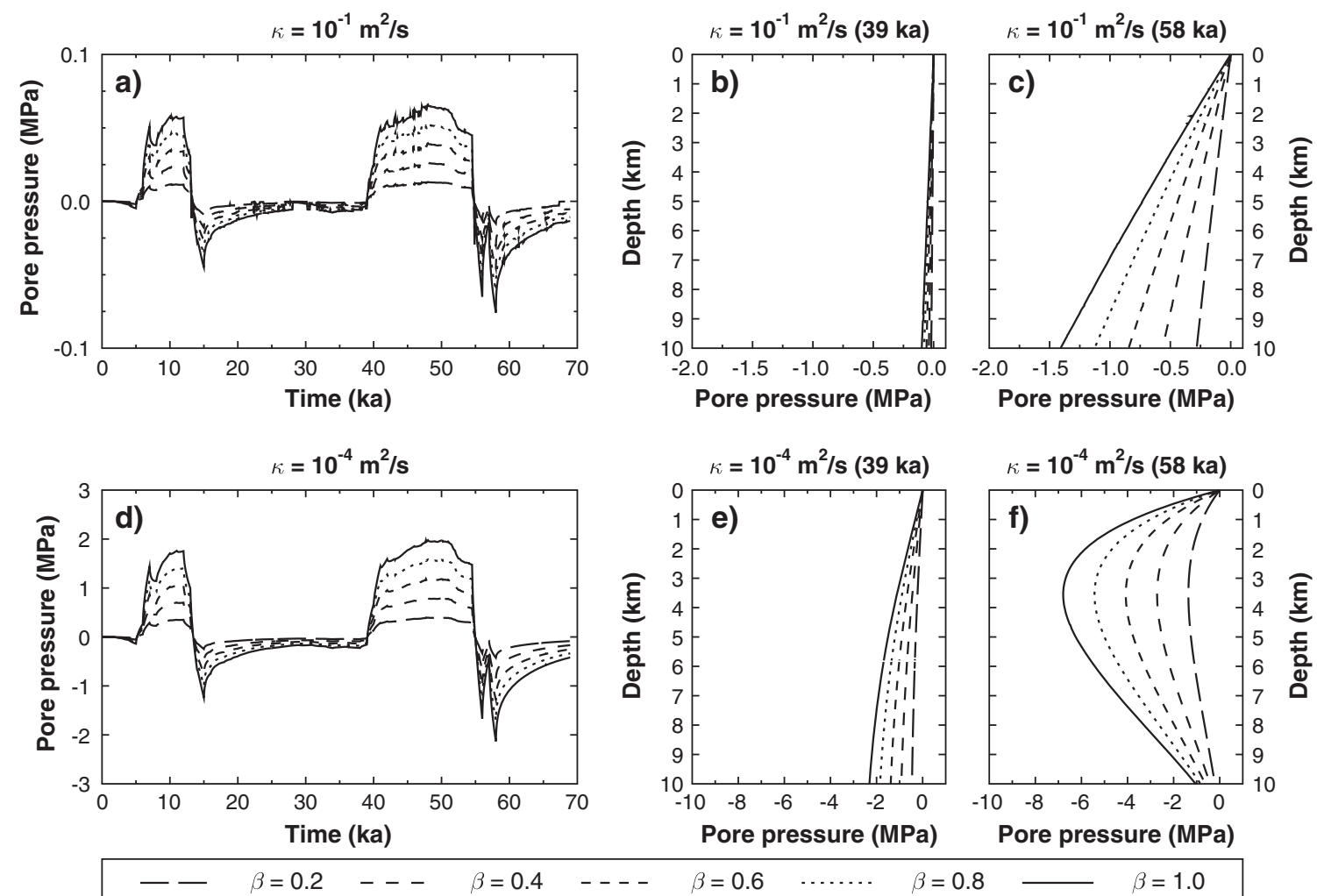

Figure 3. Mechanically induced pore pressures calculated by use of equation (2) with water pressure at the ice/bed interface, $p_{0}(t)$, set at zero. (a) Temporal evolution of the pore pressure at $500 \mathrm{~m}$ depth for a diffusivity of $\kappa=1 \times 10^{-1} \mathrm{~m}^{2} / \mathrm{s}$, (b and c) corresponding pore pressures as functions of depth when the ice margin passes over the site after $39 \mathrm{ka}$ and after $58 \mathrm{ka}$, respectively. $(\mathrm{d}-\mathrm{f})$ Equivalent pore pressures evaluated using a diffusivity of $\kappa=1 \times 10^{-4} \mathrm{~m}^{2} / \mathrm{s}$. Note differences in axis scales.

[cf. Swedish Nuclear Fuel and Waste Management Company (SKB), 2008]. Here the hydromechanical properties are represented as uniform values of hydraulic diffusivity (see section 3.4). Given that the minor principal stress component is vertical at all times and at all depths at the Forsmark site (cf. section 2.2), it is sufficient to investigate the potential for hydraulic jacking of horizontal fractures. The maximum jacking depth is the maximum depth $(y)$ for which the pore pressure is equal to the sum of the vertical stress and the tensile strength $(T)$, i.e.,

$$
p(x, y)+\rho_{w} g y=\rho_{i} g h(x)+\rho_{r} g y+T,
$$

where $\rho_{w}$ is the density of water, $\rho_{i}$ is the density of ice, $\rho_{r}$ is the density of rock, $g$ is the acceleration due to gravity, and $h$ is the local ice sheet thickness. In the following, we assume that the fractures have no tensile strength, as this approach will give the greatest maximum jacking depth.

\subsection{Ice Sheet Thickness}

[18] The thickness $(h)$ as function of horizontal position $(x)$ of the frontal region of the ice sheet is represented by a generic two-dimensional steady state profile following [Paterson, 1994]

$$
h(x, t)=h_{\max }(t)\left[1-\left(\frac{w(t)-x}{w(t)}\right)^{4 / 3}\right]^{3 / 8},
$$

where $h_{\max }$ is the maximum thickness and the slope width $w$ is the horizontal distance from the ice margin to the position of maximum thickness. The maximum thickness and slope width at glacial maximum are set at 3 and $400 \mathrm{~km}$, respectively. This combination of parameters yields a profile that is of adequate steepness compared with the reconstructed advancing Weichselian ice sheet but is considerably steeper than the corresponding retreating ice sheet profile [SKB, 2010a]. Changes in thickness as the ice margin advances or retreats are obtained by varying the parameters $h_{\max }$ and $w$.

\subsection{Water Pressure at Ice/Bed Interface}

[19] The water pressure at the ice/bed interface is mainly determined by melting and drainage. In an undrained system, the water pressure is given by the ice load. A common approximation for warm-based ice sheets is to assume that the maximum water pressure at the ice/bed interface corresponds to $90 \%$ of the ice sheet thickness [e.g., Bense and Person, 2008; Moeller et al., 2007], which is equivalent to about $98 \%$ of the mechanical load (cf. Figure $2 \mathrm{c}$ ). This value is used as reference throughout this paper. However, we expect that the pressure will fluctuate significantly over the course of a year. A generic example of such seasonal pressure variations is presented in Figure $4 \mathrm{a}$ where the ratio of water pressure at the ice/bed interface to maximum boundary pressure varies between zero during the winter season and one during the summer season with a short pressure peak in between representing spring conditions. A one-dimensional 

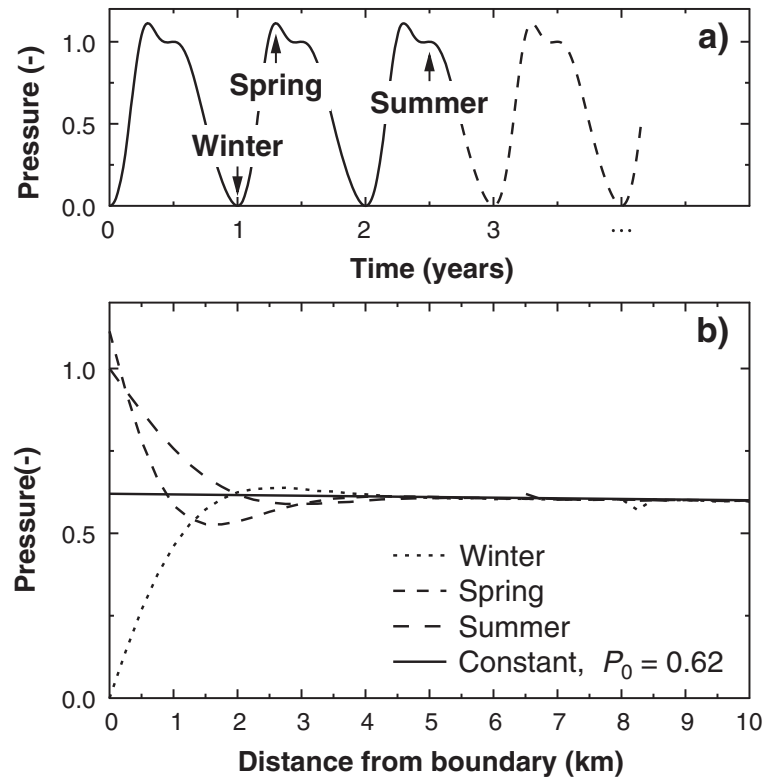

Figure 4. (a) Example of normalized boundary water pressure with seasonal variations. (b) Corresponding excess pore pressure after 10,000 years as functions of distance to the pressurized boundary assuming a hydraulic diffusivity of $10^{-1} \mathrm{~m}^{2} / \mathrm{s}$.

expression of the pore pressure evolution $(p)$ as function of the distance $(x)$ from the pressurized boundary (cf., e.g., Figure 2b) is given by Carslaw and Jaeger [1959]:

$$
p(x, t)=\frac{2}{\sqrt{\pi}} \int_{x / \sqrt{4 \kappa t}}^{\infty} p_{0}\left(t-\frac{x^{2}}{4 \kappa \eta^{2}}\right) \exp \left(-\eta^{2}\right) \mathrm{d} \eta .
$$

Figure $4 \mathrm{~b}$ shows the resulting pore pressure after 10,000 years evaluated at times corresponding to winter, spring, and summer, respectively, as functions of distance from the boundary. At positions further away than about $2 \mathrm{~km}$ from the boundary, the seasonal variations are not noticed and all three curves coincide with a corresponding model in which the boundary pressure is kept at a constant effective value. Note that this distance depends on the diffusivity assumed for the rock mass. If the diffusivity is higher than the value $\left(1 \times 10^{-1} \mathrm{~m}^{2} / \mathrm{s}\right)$ used in Figure $4 \mathrm{~b}$, the distance seasonal variations are noticeable is longer. Given the seasonal pressure variations in Figure $4 \mathrm{a}$, the effective boundary pressure corresponds to about $62 \%$ of the pressure during the summer season. However, the impact of the spring peak will depend on the time frame of the pressure peak. A much shorter peak than the one assumed here is unlikely to have a significant influence on the effective boundary pressure, i.e., the effective boundary pressure would be $50 \%$ of the maximum boundary pressure.

\subsection{Properties of the Bedrock}

[20] Although there exists a detailed site descriptive model for the candidate area of the nuclear waste repository at Forsmark [SKB, 2008], the modeling work conducted here involves significantly larger volumes of rock than those considered for the repository. However, representative values for the properties of a fractured rock mass at these scales are not well known. For the purpose of this study, we assume that the hydraulic properties of the rock mass can be represented either by one uniform global value of the hydraulic diffusivity, i.e., ratio of hydraulic conductivity to threedimensional coefficient of specific storage, or by layers of uniform hydraulic diffusivity. The choice of layers is based on the depth intervals for the hydraulic conductivity shown in Table 1. The three-dimensional coefficient of specific storage was not evaluated in the site investigation of Forsmark. However, it can be calculated from the elastic properties and effective porosity of the rock and the density and bulk modulus of water [see, e.g., Neuzil, 2003]. Figure 5 shows the coefficient of specific storage as functions of the Biot coefficient $(\alpha)$ evaluated for rock mass properties considered relevant for the Forsmark site (cf. Table 1). As an approximation to be used in the subsequent analyses, the value of the coefficient of specific storage is set at $1 \times 10^{-7} \mathrm{~m}^{-1}$. Dividing the values given in Table 1 for the hydraulic conductivity of the rock mass at different depths by the coefficient of specific storage yields values of the hydraulic diffusivity of the order of $\sim 10^{-4} \mathrm{~m}^{2} / \mathrm{s}$ for the rock below $400 \mathrm{~m}$ and in the range $1 \times 10^{-2}-1 \times 10^{-1} \mathrm{~m}^{2} / \mathrm{s}$ for the entire rock mass.

\section{Jacking Depth Assessment}

\subsection{Description of Modeling Cases}

[21] The climate preceding each glacial advance is characterized as cold, and the Forsmark site will be subjected to permafrost conditions reaching a maximum depth of 180$260 \mathrm{~m}$ [Hartikainen et al., 2010]. In SKB's permafrost modeling [SKB, 2006], the permafrost stopped growing and started to degrade when the ice sheet began to cover the site, which implies that there may be high water pressures at some distance from the ice margin. Since permafrost can be considered to be more or less impermeable [e.g., Vidstrand, 2003 ] and therefore reduces or prevents vertical and lateral flow of groundwater, it may, therefore, be possible for high pore pressures to build up within the rock mass beneath the permafrost (Figure 2b). During periods of warm-based ice cover, the pore pressure will continue to build up beneath the ice sheet. Particularly in low-permeable rocks, a significant proportion of the pore pressures may be retained by the

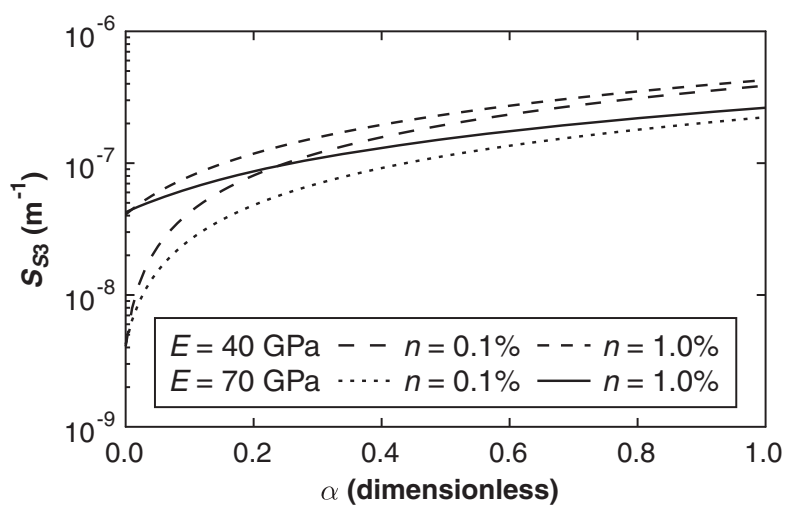

Figure 5. Calculated values of the three-dimensional coefficient of specific storage $\left(S_{S 3}\right)$ as functions of the Biot coefficient $(\alpha)$ in the range 0 to 1 . The density and bulk modulus of water are set at $1000 \mathrm{~kg} / \mathrm{m}^{3}$ and $2.2 \mathrm{GPa}$, respectively. 
Table 1. Typical Hydromechanical Properties Relevant for Present-Day Conditions at the Forsmark Site, Compiled From [Follin et al., 2007; Glamheden et al., 2007b; Mas Ivars and Hakami, 2005; Swedish Nuclear Fuel and Waste Management Company (SKB) 2008]

\begin{tabular}{lcc}
\hline Parameter & Unit & Value \\
\hline $\begin{array}{l}\text { Hydraulic conductivity a } \\
\text { All rock mass }\end{array}$ & $\mathrm{m} / \mathrm{s})$ & \\
100-200 m depth & & $10^{-9}-10^{-8}$ \\
200-400 m depth & & $5.2 \times 10^{-7}$ \\
$>400$ m depth & & $6.3 \times 10^{-10}$ \\
Effective porosity $^{\mathrm{b}}(n)$ & $\mathrm{GPa}$ & $0.1-1$ \\
Young's modulus $^{\mathrm{c}}(E)$ & dimensionless & $40-70$ \\
Poisson's ratio $(\nu)^{\text {Density of rock }\left(\rho_{r}\right)}$ & $\mathrm{kg} / \mathrm{m}^{3}$ & 0.24 \\
Density of water $^{\mathrm{d}}\left(\rho_{w}\right)$ & $\mathrm{kg} / \mathrm{m}^{3}$ & 2700 \\
Density of ice $^{\mathrm{e}}\left(\rho_{i}\right)$ & $\mathrm{kg} / \mathrm{m}^{3}$ & 1000 \\
\hline
\end{tabular}

${ }^{a}$ No significant surface denudation is expected to take place that could significantly alter the hydraulic conductivity values over a time scale of approximately $100 \mathrm{ka}$ [cf. $S K B, 2010 \mathrm{a}$, Table 3-17].

${ }^{\mathrm{b}}$ Typical range of variation for fractured crystalline rocks.

${ }^{c}$ Range of variation depends on scale. Higher value is relevant in the repository region. The lower value is an estimate suggested to be relevant on the scale of a glaciation.

${ }^{\mathrm{d}}$ Density of pure water at atmospheric pressure and $+4^{\circ} \mathrm{C}$ [e.g., Haynes, 2013].

${ }^{\mathrm{e}}$ Density of hexagonal ice at atmospheric pressure and $0^{\circ} \mathrm{C}$ [e.g., Haynes, 2013].

rock as the ice margin retreats at the end of the glaciation (Figure 2c).

[22] This has been used to set up two modeling cases for which jacking at depths larger than a few tens of meters is judged to be a theoretical possibility: first, periods of combined glacial and permafrost conditions and second, periods of rapid glacial retreat. The case of combined glacial and permafrost conditions is investigated by use of numerical finite element models, whereas the case of a retreating ice front is investigated by use of specifically derived two-dimensional analytical expressions.

\subsection{Combined Glacial and Permafrost Conditions}

\subsubsection{Numerical Pore Pressure Model}

[23] The pore pressure evolution is modeled using the general purpose finite element code Code_Bright [International Center for Numerical Methods in Engineering, 2004]. Here the rock mass is represented by a large rectangular region subdivided into three layers representing a $200 \mathrm{~m}$ thick impermeable permafrost region, the uppermost $400 \mathrm{~m}$ of rock with hydraulic diffusivity between $1 \times 10^{-2} \mathrm{~m}^{2} / \mathrm{s}$ and $1 \times 10^{-1} \mathrm{~m}^{2} / \mathrm{s}$, and the rock mass at larger depths with diffusivity set at $1 \times 10^{-4} \mathrm{~m}^{2} / \mathrm{s}$ (see Figure 6 for a schematic illustration).

[24] The model's top boundary that represents the ground surface has prescribed fluid pressure conditions at all positions where the ice sheet is not in contact with the permafrost region. All other model boundaries are impermeable. We assume that the permafrost degrades linearly from below, which results in a constant distance between the permafrost melt zone and the ice margin as the ice front advances (cf. Figure 6). Here the advancing ice front is approximated by stationary conditions, and the permafrost degradation rate is based on the reference case in SKB's SR-Can safety assessment $[S K B, 2006]$ for which the distance between the permafrost melt zone and the ice margin is approximately $170 \mathrm{~km}$. The pore pressure is set at zero initially, and all results are evaluated after 10,000 years from the beginning of the glaciation.

\subsubsection{Results}

[25] Figure 7 shows the pore pressure and associated maximum jacking depth beneath the ice margin as functions of the lateral distance between the permafrost melt zone and the ice margin. Since the pore pressure beneath the permafrost is proportional to the boundary pressure at the melt zone and the distance $(d)$ between the melt zone and the ice margin remains constant as the ice front advances, $d$ is related to the permafrost degradation rate $\left(v_{p}\right)$ through the expression $d=v_{i} \times p_{d} / v_{p}$, where $v_{i}$ is the ice front advance rate and $p_{d}$ is the permafrost depth. This relationship has been used to scale the pore pressure beneath the ice margin to the boundary water pressure in order to account for different permafrost degradation rates using the same model.

[26] For SKB's reference degradation rate (denoted SRCan in Figure 7), hydraulic jacking is not initiated at any depth. The maximum jacking depth is, however, highly dependent on the assumption of the hydraulic diffusivity in the upper $400 \mathrm{~m}$ of rock and the distance between the melt zone and the ice margin. For hypothetical, worst case, margin melt zone distance assumptions and assuming full water pressure ( $98 \%$ of the mechanical load) at the ice/bed interface, the maximum jacking depth is about $230-350 \mathrm{~m}$ depending on the hydraulic diffusivity in the upper $400 \mathrm{~m}$ of the rock. These values are likely to be significantly exaggerated when considering the effects of seasonal variations in the water pressure at the ice/bed interface (Figure $4 \mathrm{~b}$ ). Given that the effective water pressure is about $50-60 \%$ of the full water pressure ( $98 \%$ of the mechanical load), the pore pressure beneath the permafrost and the corresponding maximum jacking depth can be reduced by $40-50 \%$. Thus, the maximum jacking depth during combined glacial and permafrost conditions is not likely to be more than about $200 \mathrm{~m}$ (Figure 7) even for hypothetical, worst case, permafrost degradation rate assumptions.

\subsection{Glacial Retreat}

\subsubsection{Conceptual Model}

[27] The ice sheet is assumed to be warm-based at all times, and the pore pressure evolution is analyzed for one advance-retreat cycle corresponding to the last (major) cycle

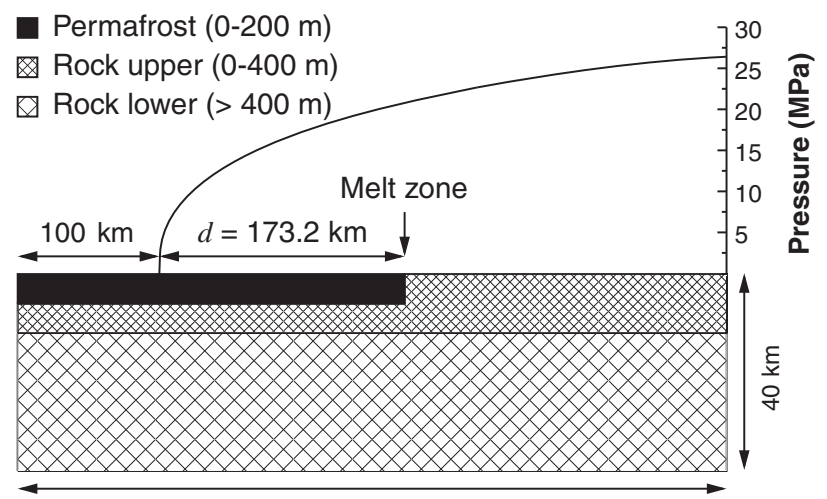

$500.5 \mathrm{~km}$

Figure 6. Schematic illustration of Code_Bright model (not to scale). 


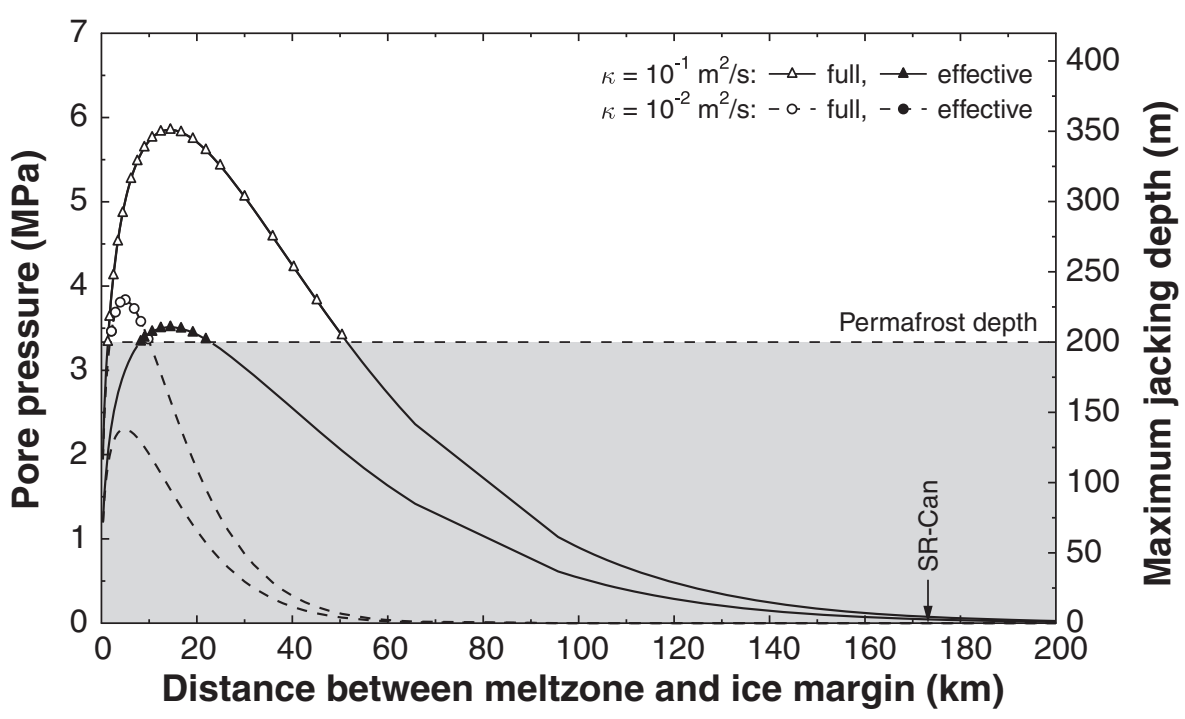

Figure 7. Pore pressure, evaluated beneath the ice margin, and corresponding maximum jacking depth during combined glacial and permafrost conditions as functions of the distance between permafrost melt zone and ice margin (measure of permafrost degradation rate) for two assumptions regarding hydraulic diffusivity in the upper rock layer. Empty symbols represent the case with "full" water pressure at the ice/bed interface ( $98 \%$ of the mechanical load), whereas the pressures/jacking depths represented by filled symbols have been reduced by $40 \%$ to account for seasonal variations in boundary pressure. Curves without plot symbols located within the gray shaded area represent pore pressures, which are too low to initiate hydraulic jacking beneath the permafrost.

in Figure 1a. In order to account for uncertainties regarding the growth and decay of the ice sheet, two sets of pressure boundary conditions are considered based on the approximation of the ice sheet profile (see Figure 8). First, the ice sheet thickness and slope width increase/decrease linearly with time (keeping the ratio between them constant) as the ice front advances/retreats (denoted BC 1); second, the maximum ice sheet thickness and slope width remain constant as the ice front advances or retreats (denoted BC 2).

\subsubsection{Analytical Solutions}

[28] The general solution to the fluid flow equation (3) as a function of the horizontal position $(x)$, depth below the ground surface $(y)$ and time $(t)$ in a semi-infinite solid in which the pore pressure is initially zero and the hydraulic properties are represented by a globally valid hydraulic diffusivity is given by (see Appendix A, section A2 for derivation)

$$
\begin{aligned}
p(x, y, t)= & \frac{2}{\pi} \int_{y / \sqrt{4 \kappa t}}^{\infty}\left[\int_{-\infty}^{\infty} f\left(x+y \frac{\eta}{\mu}, t-\frac{y^{2}}{4 \kappa \mu^{2}}\right)\right. \\
& \left.\times \exp \left(-\mu^{2}\right) \exp \left(-\eta^{2}\right) \mathrm{d} \eta\right] \mathrm{d} \mu,
\end{aligned}
$$

where $f(x, t)$ is the temporally and spatially varying water pressure at the ice/bed interface, and $\eta$ and $\mu$ are the (dimensionless) integration variables.

[29] Since a mechanically uncoupled analysis may underestimate the pore pressure during the advancement of the ice sheet (cf. Figure 3), a second case is considered where the ice front retreats from steady state conditions. In the absence of permafrost, the steady state pore pressure can be considered an upper bound approximation of the pore pressure during ice sheet advancement. The ice sheet has been stationary for an infinite amount of time, and the highest possible pore pressures have been allowed to build up everywhere. The expression for the steady state pore pressure $\left(p_{s s}\right)$ is given by Carslaw and Jaeger [1959]

$$
p_{S S}(x, y)=\frac{1}{\pi} \int_{-\infty}^{\infty} \frac{f_{0}\left(y x^{\prime}+x\right)}{1+x^{\prime 2}} \mathrm{~d} x^{\prime},
$$

where $f_{0}(x)$ is the water pressure distribution at the boundary representing the ground surface for stationary conditions.

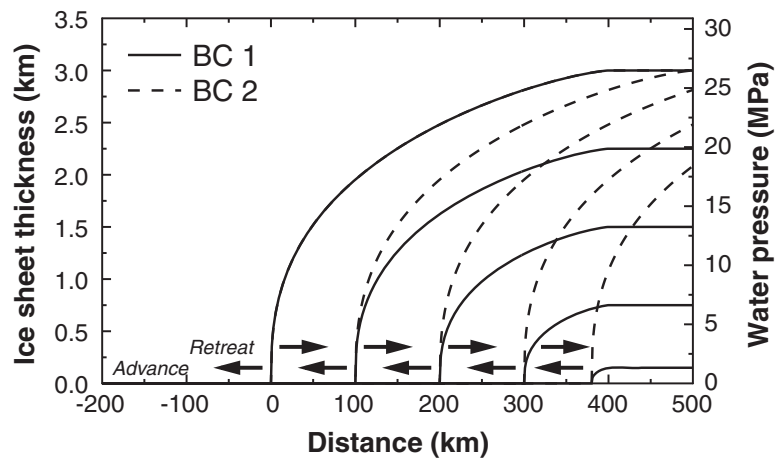

Figure 8. Approximations of ice sheet evolution at the Forsmark site. The maximum thickness either increases/decreases linearly with time keeping the ratio between thickness and slope width constant (BC 1) or is kept constant with time (BC 2). The water pressure at the ice/bed interface corresponds to $98 \%$ of the mechanical load. 


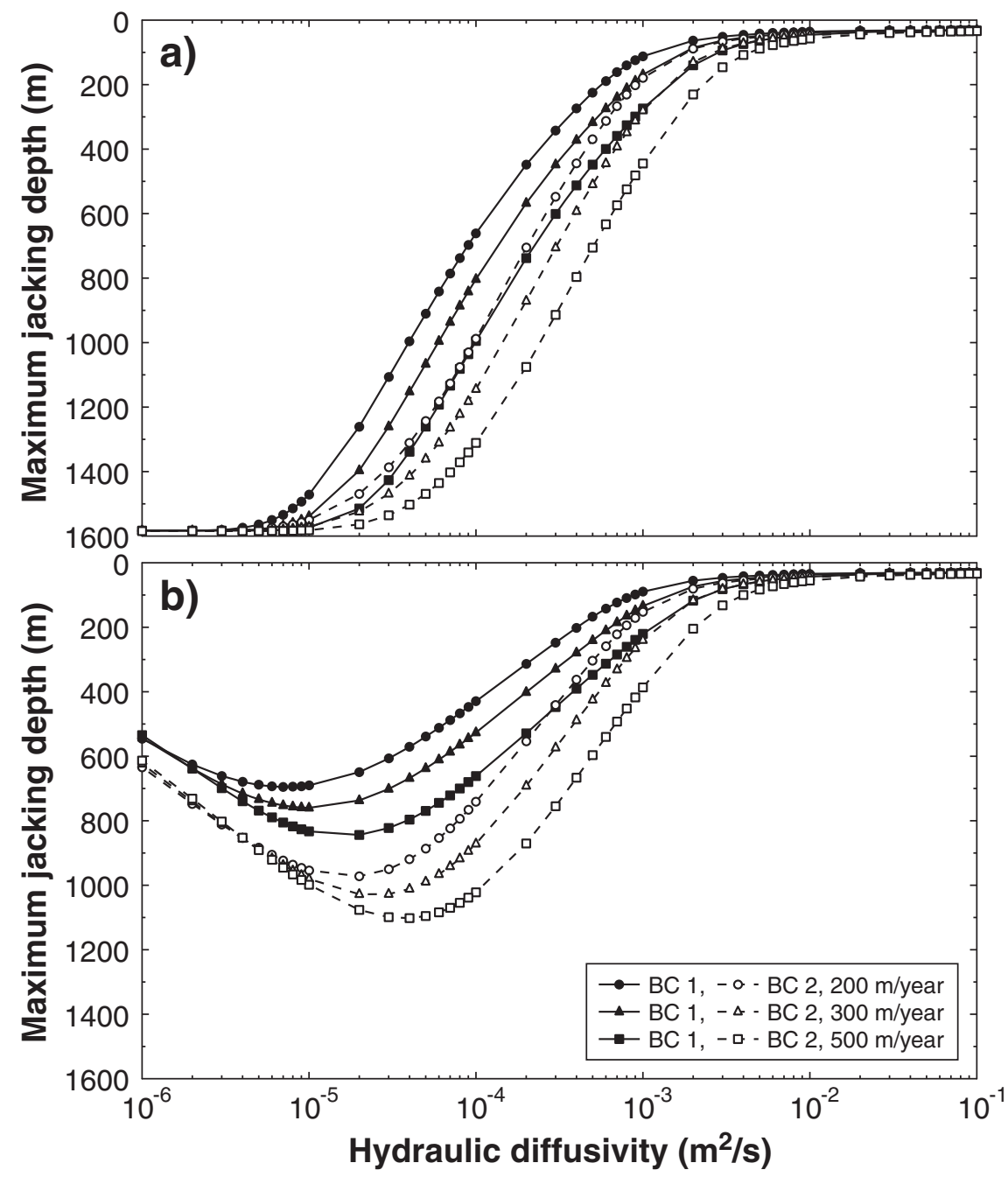

Figure 9. Maximum jacking depths as functions of the hydraulic diffusivity of the rock assuming retreat at $200-500 \mathrm{~m} / \mathrm{yr}$ from (a) steady state conditions (cf. equation (9)) or (b) advancement at $40 \mathrm{~m} / \mathrm{yr}$ for 10,000 years and thereafter retreat at 200-500 m/yr (cf. equation (7)). BC 1 and BC 2 relate to the boundary conditions shown in Figure 8.

The transient pore pressure evolution during glacial retreat is then given by (see Appendix A, section A2 for derivation)

$$
\begin{aligned}
p(x, y, t)= & p_{S S}(x, y)-\frac{2}{\pi} \int_{y / \sqrt{4 \kappa t}}^{\infty}\left[\int_{-\infty}^{\infty} f_{0}\left(x+y \frac{\eta}{\mu}\right)\right. \\
& \left.\times \exp \left(-\mu^{2}\right) \exp \left(-\eta^{2}\right) \mathrm{d} \eta\right] \mathrm{d} \mu \\
+ & \frac{2}{\pi} \int_{y / \sqrt{4 \kappa t}}^{\infty}\left[\int_{-\infty}^{\infty} f\left(x+y \frac{\eta}{\mu}, t-\frac{y^{2}}{4 \kappa \mu^{2}}\right)\right. \\
& \left.\times \exp \left(-\mu^{2}\right) \exp \left(-\eta^{2}\right) \mathrm{d} \eta\right] \mathrm{d} \mu .
\end{aligned}
$$

\subsubsection{Results}

[30] Figure 9 shows the maximum jacking depth as the ice front retreats during the end of the glacial period as functions of the hydraulic diffusivity for frontal retreat rates in the range $200-500 \mathrm{~m} / \mathrm{yr}$ assuming (a) that the pore pressure has reached steady state conditions before retreat and (b) that the front of an ice up to $3 \mathrm{~km}$ thick has advanced at $40 \mathrm{~m} / \mathrm{yr}$ for 10,000 years before retreat.

[31] For high values of the hydraulic diffusivity $(>5 \times$ $10^{-3} \mathrm{~m}^{2} / \mathrm{s}$ ), the maximum jacking depth is determined by the steepness of the ice front and is approximately independent of the retreat speed and periods of preceding stationary conditions.

[32] For very low values of the hydraulic diffusivity $\left(<5 \times 10^{-5} \mathrm{~m}^{2} / \mathrm{s}\right)$, provided that the pore pressures have reached a steady state before retreat, most of the glacially induced pore pressure is retained by the rock. In this case, the retreat speed is relatively unimportant and the maximum jacking depth is determined by the thickness of the ice (Figure 9a). However, for a finite approach time (here 10,000 years at $40 \mathrm{~m} / \mathrm{yr}$ ), the high pressures have not propagated sufficiently far down into the rock to initiate jacking at equally large depths. The largest jacking depths are found in rock with somewhat higher diffusivity, and the maximum jacking depths are highly dependent on the retreat speed (Figure 9b). 
[33] Relevant values for the frontal advance and retreat rates at the Forsmark site are estimated to be about 40 and $300 \mathrm{~m} / \mathrm{yr}$, respectively, based on those in the Weichselian ice sheet reconstruction [SKB, 2010a]. Given the range of hydraulic diffusivity values at the site (between $1 \times 10^{-2} \mathrm{~m}^{2} / \mathrm{s}$ and $1 \times 10^{-1} \mathrm{~m}^{2} / \mathrm{s}$ ), the maximum jacking depth is approximately $50-75 \mathrm{~m}$ regardless of the time frame of preceding stationary conditions or retreat rates in the range $200-500 \mathrm{~m} / \mathrm{yr}$.

\section{Discussion and Summary}

\subsection{General}

[34] This paper comprises results from a generic study of the potential for hydraulic jacking of subhorizontal fractures at the Forsmark site. Given SKB's reference glacial scenario [SKB, 2010a], two regions or positions have been identified where the jacking depth is expected to be maximized. These are in front of an advancing warm-based ice sheet with extensive proglacial permafrost and behind the front of a retreating warm-based ice. A generic representation of a theoretical steady state ice front profile [Paterson, 1994] with a maximum thickness of $3000 \mathrm{~m}$ has been used throughout the study. Assessments of the potential of hydraulic jacking at different depths have been carried out, assuming that the glacially induced vertical stress is equal to the weight of the ice, that the maximum water pressure at the ice/rock interface is about $98 \%$ of the ice load, and that the total vertical stress (i.e., the sum of the rock overburden and the local ice load) is the minor principal stress in all models at all times. The maximum jacking depths are estimated to be about $200 \mathrm{~m}$ during combined glacial and permafrost conditions (see Figure 7) and 50-75 $\mathrm{m}$ during glacial retreat (see Figure 9). For a more blocky representation of the rock mass, the effect of the flexural stresses may be overestimated and the minor principal stress might not be vertical at all times. On the other hand, a rock mass with higher fracture frequency will also have higher permeability. During glacial retreat, this will contribute to a reduced maximum jacking depth, whereas during combined glacial and permafrost conditions, the converse is likely to be the case (i.e., the maximum jacking depth will be increased).

\subsection{Relevance of Models}

\subsubsection{Ice Sheet Representation}

[35] Since there are no means of anticipating the dimensions of the next major ice sheet, SKB exemplifies future climate variations with a repetition of the Weichselian glaciation period using a high-resolution regional ice sheet model based on the University of Maine Ice Sheet Model [SKB, 2010 b, section 3.22, and references therein]. This ice sheet model uses climatic variations as its driving force [e.g., Lund et al., 2009; SKB, 2010b]. It, therefore, differs from other models [e.g., Lambeck, 2005; Lambeck et al., 2010; Peltier, 2004] where ice sheet extents are constructed from geological markers and the ice sheet thickness is calibrated such that the response of an associated Earth model fits available data [e.g., Lund et al., 2009]. Comparisons between some of the different ice models commonly used in modeling of the Weichselian glaciation in Fennoscandia are given by Lund et al. [2009] and Steffen and Wu [2011].
[36] The generic two-dimensional ice sheet profile used in the present modeling work is considered to be steep enough to represent the advancing Weichselian ice sheet at the Forsmark site and is considerably steeper than expected of ice profiles during stationary and retreating phases $[S K B$, 2010a]. Results from modeling of the largest Fennoscandian ice sheets during the past $2 \mathrm{Ma}$, i.e., the Saalian ice sheet, shows that the maximum thickness at the Forsmark site was in the range 3100-3400 $\mathrm{m}$ [SKB, 2010a], i.e., in good agreement with the maximum thickness in our models. Although the Saalian ice sheet at its peak reached about $1000 \mathrm{~km}$ further east and about $200 \mathrm{~km}$ further south than the Weichselian ice sheet $[S K B, 2010 \mathrm{a}]$, the areal extent of the two-dimensional ice sheet profile used in the present modeling work is infinite in the direction perpendicular to the flow. Additional sensitivity tests based on extreme cases indicate that it is unlikely that the ice sheet would exceed a thickness of $3700 \mathrm{~m}$ at the site [SKB, 2010a]. Therefore, the maximum ice sheet thickness of $3000 \mathrm{~m}$, areal extent, and frontal steepness used in the modeling work appear to be adequate for the Forsmark site. However, spatial variations in ice sheet thickness along the ice front, e.g., due to bays and valleys, cannot be modeled using the two-dimensional approach presented here. Provided that the scale of these irregularities along the ice front are smaller than approximately a few tens of kilometers, i.e., the distance the glacially induced pore pressures can potentially be transferred, their influence on the estimated maximum jacking depths is judged to be insignificant.

\subsubsection{Water Pressure at Ice/Bed Interface}

[37] The maximum water pressure at the ice/bed interface is set at $98 \%$ of the mechanical load, which is a reasonable upper bound estimate, during ice front advance, during periods of stationary conditions and during ice front retreat, regardless of any possible discharge paths along the ice/ground interface. However, the uncertainties regarding the actual basal pressure variations beneath ice sheets are large and, in reality, the ratio between water pressure at the ice/bed interface and mechanical load is unlikely to be uniform along the flow line [e.g., Boulton et al., 2001], but the 2-D approach considered here does not allow for modeling of, e.g., subglacial tunnels or other pressure variations along the ice front. Seasonal pressure variations are noticeable within a few kilometers of the boundary (cf. Figure 4b). Further away, the pore pressure is governed by the annual average boundary pressure rather than the maximum pressure. This justifies accounting for seasonal variations during combined glacial and permafrost conditions, but not for glacial conditions without permafrost.

\subsubsection{Rock Mass Representation}

[38] All results are compiled from one- and twodimensional models of the pore pressure evolution based on the assumption that the rock mass can be treated essentially as a poroelastic continuum with a few isolated fractures. Although fluid flow in fractured crystalline rocks, such as at the Forsmark site, mainly takes place within the fracture network, the continuum representation of the rock mass can be justified if the flow is considered on a larger scale than the length of the dominating fractures [e.g., $S K B, 2010$ c]. For rock with few conductive fractures, we estimate that fracture lengths of several kilometers are needed for sufficiently 
high pore pressures to propagate undisturbed to the ice front and thereby initiate hydraulic jacking at large depths (cf. Figure 2a). Since no isolated gently dipping fractures of the required length have been observed at the Forsmark site [cf., e.g., $S K B, 2008$ ], this observation points to the very specific conditions regarding fractures and background permeability required to initiate jacking at large depths. However, this needs to be verified by use of models with an explicitly modeled fracture network.

\subsubsection{Hydraulic Properties of the Bedrock}

[39] The hydrological conditions at the Forsmark site are approximated by uniform bulk hydraulic diffusivity values. The analytical expressions, used to assess the maximum jacking depth during glacial retreat (equations (7) and (9)), do not account for the observed decreasing trend in hydraulic conductivity (cf. Table 1) with depth at the Forsmark site. However, Hökmark et al. [2010] and Lönnqvist and Hökmark [2010] have shown that, in a layered medium with high hydraulic diffusivity near the ground surface and lower diffusivity at larger depths, the low hydraulic diffusivity at large depth will reduce the upward transfer of pore pressures and will therefore contribute to a more efficient drainage of the pore pressures at more shallow depths compared with the homogeneous diffusivity models considered here.

\subsubsection{Hydromechanical Couplings}

[40] The coupling between effective stress and permeability has not been considered in any of our models. If hydraulic jacking is initiated in a fracture that has a connection to the (unpressurized) ground surface, the associated drainage along the flow path will tend to reduce the pore pressure and consequently reduces the risk of hydraulic jacking occurring below the dilated fracture. This is not considered in the estimates of the maximum jacking depths, which should therefore be considered as bounding estimates. Given that typical variations in fracture transmissivity during SKB's reference glacial cycle are in the range 50-200\% [Hökmark et al., 2010] and that the range in hydraulic diffusivity that is considered relevant for the rock at Forsmark spans more than one order of magnitude, this particular hydromechanical coupling is likely to be of subordinate importance.

[41] An indication of the influence of the flexural stresses on the excess pore pressure was found by examining solutions to equation (1) in one dimension and accounting for temporal variation in the glacially induced mean total stress. During glacial retreat, accounting for changes in the glacially induced mean total stress tends to reduce the pore pressure more quickly. These results are consistent with the approximation of uniaxial loading (cf. Appendix B). Therefore, it appears that, at least for the purpose of estimating the maximum jacking depth during glacial retreat, the mechanical impact on the pore pressure can be ignored. Although the hydromechanically coupled 1-D calculations indicate a reduction in pore pressure also during forebulge conditions (cf. Figure 3, $39 \mathrm{ka}$ ), the influence of the mechanical loading on the pore pressure evolution during combined glacial and permafrost conditions needs further investigation.

\subsection{Evaluation of Maximum Jacking Depths}

\subsubsection{Combined Glacial and Permafrost Conditions During Glacial Advance}

[42] The potential for hydraulic jacking during combined glacial and permafrost conditions has been analyzed based on the assumption that there is $100 \%$ continuous, impermeable permafrost coverage everywhere in front of the advancing ice sheet even though unfrozen parts within the permafrost body may exist [cf. Hartikainen et al., 2010]. Our results show that the two most important parameters that govern the maximum jacking depth during combined glacial and permafrost conditions are the hydraulic diffusivity of the rock mass and the horizontal distance between the ice margin and the melt zone. High values of the hydraulic diffusivity result in large jacking depths and vice versa. Since the permafrost is assumed to degrade linearly from below, the distance between the permafrost melt zone and the ice margin is constant at all times and is determined by the permafrost degradation rate and the rate at which the ice front is advancing. The impact of simultaneous permafrost degradation also from the above due to, e.g., strain heating in the basal ice can be ignored or incorporated in the case already analyzed without underestimating the maximum jacking depth. First, ignoring any drainage and pressure drawdown along the ice/bed interface will increase the pore pressure beneath the permafrost and, therefore, gives a bounding estimate of the maximum jacking depth. Second, simultaneous degradation from above and below would imply an effectively faster degradation rate. By evaluating the maximum jacking depth as function of distance from the melt zone (rather than from degradation rate), the calculated maximum jacking depth is unaffected by the style of degradation, i.e., if it degrades only in one direction or simultaneously from above and below. The initial permafrost thickness in itself does not have a direct impact on the maximum jacking depth as the pore pressure beneath the permafrost is governed by the water pressure at the melt zone and the diffusivity of the rock mass. However, the maximum jacking depth is indirectly affected since, for a given permafrost degradation rate, the distance between the ice margin and the melt zone depends on the initial permafrost thickness. If the permafrost does not degrade as the ice front passes over it, the pore pressure will mainly be determined by the weight of the ice and the compressibility of the rock. In this case, the pore pressure beneath the ice margin will be lower than in the case where there is pressurized liquid water at some distance from the ice margin.

[43] For the reference permafrost degradation rate considered in SKB's safety assessment SR-Can [SKB, 2006], hydraulic jacking is not initiated at any depth (see Figure 7). In the worst case model, the hydraulic diffusivity is set at $10^{-1} \mathrm{~m}^{2} / \mathrm{s}$ in the upper $400 \mathrm{~m}$ of rock and $10^{-4} \mathrm{~m}^{2} / \mathrm{s}$ elsewhere, the permafrost degradation rate is $0.53 \mathrm{~m} / \mathrm{a}$, and the permafrost layer is assumed to have first degraded 10,000 years prior to the ice front arriving at the site. For this combination of parameters, the maximum jacking depth is $350 \mathrm{~m}$. For the lower value of the hydraulic diffusivity considered relevant for the upper $400 \mathrm{~m}$ of rock $\left(10^{-2} \mathrm{~m}^{2} / \mathrm{s}\right)$, hydraulic jacking below the permafrost is unlikely. However, for all realistic permafrost degradation rates, the distance between the melt zone and the ice margin is at least a few kilometers, which implies that the maximum pore pressure and corresponding maximum jacking depth beneath the ice margin is governed by the annual average boundary pressure rather than the maximum pressure (see Figure 4). Given that we estimate the annual average pressure to be in the range $50-60 \%$ of the maximum pressure, the maximum 
jacking depth is likely to be reduced by $40-50 \%$, i.e., to at most about $200 \mathrm{~m}$.

[44] An additional factor contributing to a reduction of the maximum jacking depth is the presence of open taliks (unfrozen parts of the permafrost body) or other discontinuities within the permafrost, which will reduce the pore pressure beneath the permafrost [Boulton and Caban, 1995]. Results from SKB's modeling work for the SR-Site safety assessment [Hartikainen et al., 2010] indicate that, under certain circumstances, taliks will form a few kilometers from the repository region beneath future lakes site that will develop due to isostatic uplift. However, taliks cannot properly be incorporated into the 2-D model.

\subsubsection{Glacial Retreat}

[45] Given the frontal slope and maximum ice sheet thickness, there are three parameters that influence the maximum jacking depth during the retreat phase: first, the bulk hydraulic diffusivity of the rock mass, second, the speed by which the ice front is approaching or time frame of periods of stationary conditions before the retreat, and third, the frontal retreat rate. In the range of bulk hydraulic diffusivity values considered relevant for the uppermost $400 \mathrm{~m}$ of rock at the Forsmark site (between $1 \times 10^{-2} \mathrm{~m}^{2} / \mathrm{s}$ and $1 \times 10^{-1} \mathrm{~m}^{2} / \mathrm{s}$ ), the maximum jacking depth is insensitive to details regarding the other two parameters (Figure 9). Relevant values for the frontal advance and retreat rates at the Forsmark site are estimated to be 40 and $300 \mathrm{~m} / \mathrm{yr}$, respectively, based on those in the Weichselian ice sheet reconstruction $[S K B, 2010 \mathrm{a}]$. Even for an infinite duration of stationary ice-frontal conditions (steady state conditions) prior to glacial retreat and the fastest considered retreat rate (500 $\mathrm{m} / \mathrm{yr}$ ), the maximum jacking depth is unlikely to be more than $50-75 \mathrm{~m}$.

[46] Should permafrost be present during glacial retreat, high pore pressure could be retained within the rock mass due to poor drainage through the permafrost. This has been suggested as a possible cause of the postglacial faulting observed in northern Scandinavia [Lagerbäck and Sundh, 2008]. Also, local regions of frozen rock or cold-based conditions around the margin of a very thin ice front could be sufficient to initiate hydraulic jacking at a depth of a few tens of meters [Pusch et al., 1990]. However, in the current reference deglaciation scenario for Forsmark [SKB, 2010a], the ice sheet will be warm-based and the site will be submerged. Therefore, the potential for permafrost to be present during glacial retreat is judged to be low at the Forsmark site.

\section{Conclusions}

[47] To conclude, given a future glacial period with similar characteristics as SKB's reconstruction of the Weichselian glaciation at the Forsmark site [SKB, 2010a], hydraulic jacking is likely to be a local, near-surface phenomenon. However, there are no means of anticipating the dimensions of the next major ice sheet. For an ice sheet with significantly different characteristics, e.g., larger thickness, steeper frontal slope, longer periods of ice cover, or coldbased conditions, the potential for hydraulic jacking may be different. Regardless of ice sheet model, hydraulic jacking may be initiated on a smaller scale around repository openings where stress redistribution effects may have reduced the in situ compression of suitably oriented fractures [e.g.,
Hökmark et al., 2010]. Its hydraulic impact is, however, judged to be limited [Swedish Nuclear Fuel and Waste Management Company, 2010d] and does not influence the large-scale potential for jacking. The pore pressure is also an important input parameter to stability analyses of fractures and fracture zones [e.g., Fälth et al., 2010; Hökmark et al., 2010]. For that purpose, further refinements of the pore pressure model may be needed. Future work may include an extension of the model to 3-D in order to investigate the impact of fluid flow also in a fracture network or adding 3-D aspects such as taliks and variations in areal extent of the permafrost.

\section{Appendix A: Derivations of Analytical Solutions to Equation of Fluid Flow}

\section{A1. 1-D Expressions}

[48] The mechanically coupled equation for fluid flow (1) is solved analytically in one dimension by examining functions of the form, $p(y, t)=u(y, t)+\beta \sigma_{t}(t)$, where $u$ is a solid with initial condition $u(y, t=0)=0$ and boundary conditions $u(y=0, t)=p_{0}(t)-\beta \sigma_{t}(t)$ and $\lim _{y \rightarrow \infty} \partial u(y, t) / \partial y \rightarrow 0$. Since $\sigma_{t}$ is not a function of the spatial coordinate $y$, inserting the expression for $p$ into equation (1) yields a homogeneous partial differential equation for $u$ :

$$
\frac{\partial^{2} u}{\partial y^{2}}=\frac{1}{\kappa} \frac{\partial u}{\partial t}
$$

[49] The solution to equation (A1) is given by Carslaw and Jaeger [1959]:

$$
\begin{aligned}
u(y, t)= & \frac{2}{\sqrt{\pi}} \int_{y / \sqrt{4 \kappa t}}^{\infty}\left[p_{0}\left(t-\frac{y^{2}}{4 \kappa \eta^{2}}\right)\right. \\
& \left.-\beta \sigma_{t}\left(t-\frac{y^{2}}{4 \kappa \eta^{2}}\right)\right] \exp \left(-\eta^{2}\right) \mathrm{d} \eta .
\end{aligned}
$$

\section{A2. 2-D Expressions}

[50] The two-dimensional diffusion equation (3) in the half-plane $-\infty<x<\infty$ and $y \geq 0$ with initial condition $p(x, y, t=0)=0$ and boundary conditions $p(x, y=0, t)=$ $f(x, t)$ and $\lim _{y \rightarrow \infty} p(x, y, t) \rightarrow 0$ is solved by a combination of Fourier and Laplace transformations.

[51] Applying the Fourier transform in $x$ and the Laplace transform in $t$ yields an ordinary differential equation for the transformed pore pressure $(\tilde{p})$

$$
-k_{x}^{2} \tilde{p}+\frac{\partial^{2} \tilde{p}}{\partial y^{2}}=\frac{s}{\kappa} \tilde{p}
$$

with general solution

$$
\tilde{p}=A \exp \left(-\sqrt{k_{x}^{2}+\frac{s}{\kappa}} y\right)+B \exp \left(\sqrt{k_{x}^{2}+\frac{s}{\kappa}} y\right),
$$

where $A$ and $B$ are the constants of integration. The values of these are obtained from the boundary conditions to yield $A=\tilde{f}\left(k_{x}, s\right)$ and $B=0$. Thus,

$$
\tilde{p}=\tilde{f}\left(k_{x}, s\right) \exp \left(-\sqrt{k_{x}^{2}+\frac{s}{\kappa}} y\right) .
$$


Equation (A4) is inverted to the expression given for $p$ (equation (7)) using inversion tables and convolution theorems [Carslaw and Jaeger, 1959; Kreyszig, 1993].

[52] As the diffusion equation is linear, the principle of superposition applies and the solution where the pore pressure distribution is initially given by a steady state distribution, equation (8), can be found using a similar approach. This solution is found by examining functions of the form [see, e.g., Carslaw and Jaeger, 1959]:

$$
p(x, y, t)=u(x, y, t)+v(x, y, t),
$$

where $u(x, y, t)$ is the pore pressure in a solid with initially zero pressure and the plane $y=0$ (ground surface) kept at a pressure given by a function $f(x, t) ; v(x, y, t)$ is the pore pressure in a solid where the pressure is initially given by the steady state pore pressure distribution, $p_{S S}(x, y)$, due to $f_{0}(x)=f(x, t=0)$ and has zero pressure on the plane $y=0$. The equation for $u$ has been derived above and has the same form as equation (7).

[53] The expression for $v$ is obtained by introducing a third function, $w=v-p_{S S}$, then $w=0$ at $t=0$ and $w=-p_{S S}(x, t=0)=-f_{0}(x)$ at $y=0$. As $p_{S S}$ is a solution to the diffusion equation, so is $w$. The function $w$ is a special case of equation (7) with $f(x, t)=f_{0}(x)$. Thus,

$$
\begin{aligned}
v(x, y, t)= & p_{S S}(x, y)-\frac{2}{\pi} \int_{y / \sqrt{4 \kappa t}}^{\infty}\left[\int_{-\infty}^{\infty} f_{0}\left(x+y \frac{\eta}{\mu}\right)\right. \\
& \left.\times \exp \left(-\mu^{2}\right) \exp \left(-\eta^{2}\right) \mathrm{d} \eta\right] \mathrm{d} \mu .
\end{aligned}
$$

\section{Appendix B: Impact of Uniaxial Loading}

[54] A common approximation in hydromechanical modeling of glacial conditions is to assume that a large and homogeneously distributed ice sheet does not induce any lateral strain within the rock beneath it [e.g., Lemieux et al., 2008a, 2008b, 2008c; Walsh and Avis, 2010]. This approximation decouples the equations of stress or deformation from the equation of fluid flow and leads to a formulation of the latter that only incorporates changes in the vertical stress [e.g., Neuzil, 2003].

[55] For uniaxial loading, the one-dimensional equation for fluid flow (equation (1)) is given by [Neuzil, 2003]

$$
\frac{\partial^{2} p}{\partial y^{2}}=\frac{1}{\kappa_{1}} \frac{\partial p}{\partial t}-\frac{\zeta}{\kappa_{1}} \frac{\partial \sigma_{v}}{\partial t},
$$

where $\kappa_{1}=K_{H} / S_{S}\left(\mathrm{~m}^{2} / \mathrm{s}\right)$ is the hydraulic diffusivity, $S_{S}=$ $S_{S 3}(1-2 \alpha \beta(1-2 v) /[3(1-v)])\left(\mathrm{m}^{-1}\right)$ is the one-dimensional coefficient of specific storage, $\alpha$ (dimensionless) is the Biot coefficient, $v$ (dimensionless) is the Poisson's ratio, and $\zeta$ (dimensionless) is a one-dimensional loading coefficient representing change in fluid pressure to change in vertical stress under conditions of lateral confinement. The onedimensional loading coefficient can take on values between zero and one depending on the compressibility of the rock although not independently of Skempton's coefficient [cf. Neuzil, 2003].

[56] Lemieux et al. [2008a] have derived a onedimensional expression for constant rate of change of the vertical load and zero water pressure at the ground surface.
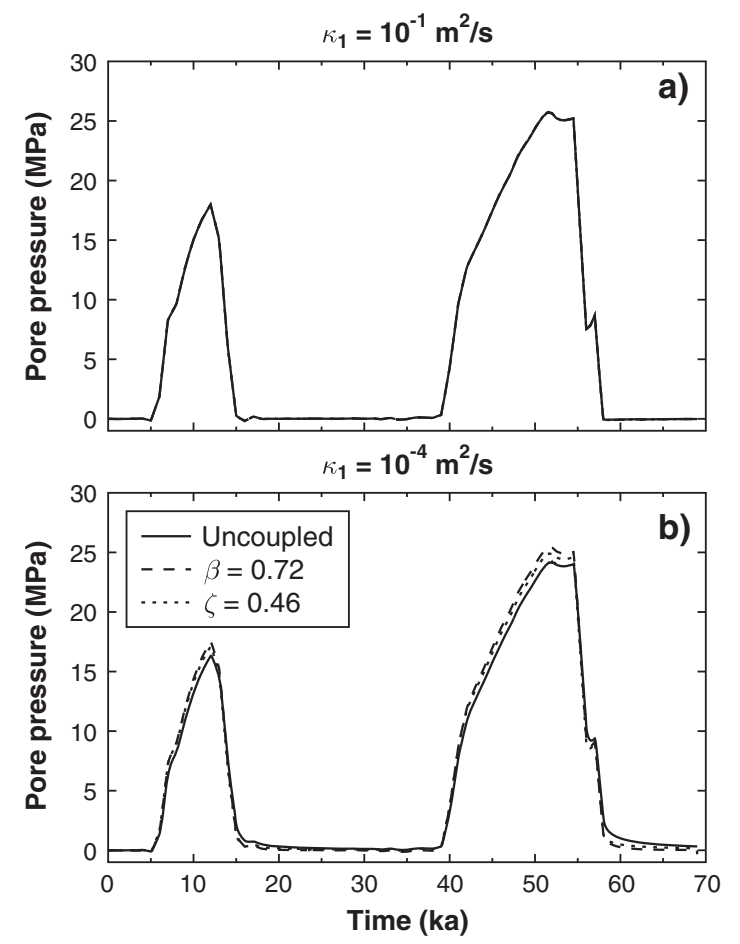

Figure B1. Comparison between the glacially induced pore pressures at $500 \mathrm{~m}$ depth obtained using a mechanically coupled model where the impact of flexural stresses is accounted for $(\beta=0.72)$, a mechanically coupled model where horizontal strains are ignored $(\zeta=0.46)$ and a mechanically uncoupled model. Here the diffusivity is (a) $\kappa_{1}=1 \times 10^{-1} \mathrm{~m}^{2} / \mathrm{s}$ and (b) $\kappa_{1}=1 \times 10^{-4} \mathrm{~m}^{2} / \mathrm{s}$. Corresponding values for $\kappa$ are obtained by putting $\alpha=0.5$ and $v=0.24$ in the expression for $S_{S 3}$ as function of $S_{S}$ given below equation (B1).

A corresponding expression for generally varying surface loads $\sigma_{v}(t)$ and changes in water pressure $p_{0}(t)$, can be derived by letting $p(y, t)=u(y, t)+\zeta \sigma_{v}(t)$ and using the method described in section A1. The resulting expression for the change in pore pressure is given by

$$
\begin{aligned}
p(y, t)= & \frac{2}{\sqrt{\pi}} \int_{y / \sqrt{4 \kappa_{1} t}}^{\infty}\left[p_{0}\left(t-\frac{y^{2}}{4 \kappa_{1} \eta^{2}}\right)\right. \\
& \left.-\zeta \sigma_{v}\left(t-\frac{y^{2}}{4 \kappa_{1} \eta^{2}}\right)\right] \exp \left(-\eta^{2}\right) \mathrm{d} \eta+\zeta \sigma_{v}(t) .
\end{aligned}
$$

[57] A comparison of the pore pressure evolution at $500 \mathrm{~m}$ depth obtained from equations (2) and (B2) is shown in Figure B1. The uncoupled solution is obtained by letting $\zeta=\beta=0$. In this example, the mean total stress and vertical stress are taken to be those at $500 \mathrm{~m}$ depth in SKB's reference glacial cycle for Forsmark (see Figure 1b) and the water pressure at the ice/bed interface is set at $98 \%$ of the glacially induced vertical stress. For both mechanically coupled solutions, the pore pressure tends to increase more quickly during the advance of the ice front than with an uncoupled analysis, whereas during the retreat phase, the coupled analyses result in a lower pore pressure. This is consistent with the results by Lemieux et al. [2008a]. 


\section{LÖNNQVIST AND HÖKMARK: ESTIMATE OF MAXIMUM JACKING DEPTHS}

[58] Acknowledgments. The authors wish to acknowledge that this work is based on a study conducted for (and funded by) SKB [Lönnqvist and Hökmark, 2010, 2012]. We thank the Associate Editor Jeremy Bassis, Geoffrey Boulton, Christopher Talbot, and one anonymous reviewer for their constructive comments that helped to improve the text.

\section{References}

Bense, V. F., and M. A. Person (2008), Transient hydrodynamics within intercratonic sedimentary basins during glacial cycles, J. Geophys. Res., 113, F04005, doi:10.1029/2007JF000969.

Boulton, G., T. Chan, R. Christiansson, L. O. Ericsson, J. Hartikainen, M. R. Jensen, F. W. Stanchell, and T. Wallroth (2004), ThermoHydro-Mechanical (T-H-M) impacts of glaciation and implications for deep geologic disposal of nuclear waste, in Coupled ThermoHydro-Mechanical-Chemical Processes in Geo-Systems. Fundamentals, Modelling, Experiments and Applications, Elsevier Geo-Engineering Book Series, vol. 2, edited by O. Stephansson et al., pp. 299-304, Elsevier, Amsterdam.

Boulton, G. S., and P. Caban (1995), Groundwater flow beneath ice sheets: Part II-Its impact on glacier tectonic structures and moraine formation, Quat. Sci. Rev., 14, 563-587.

Boulton, G. S., S. Zatsepin, and B. Maillot (2001), Analysis of groundwater flow beneath ice sheets, $S K B$ TR-01-06, Svensk Kärnbränslehantering AB (SKB), Stockholm, Sweden.

Brady, B. H. G., and E. T. Brown (1993), Rock Mechanics. For Underground Mining, 2nd ed., 571 p., Chapman \& Hall, London, U. K

Carslaw, H. S., and J. C. Jaeger (1959), Conduction of Heat in Solids, 2nd ed., 510 p., Oxford University Press, U. K

Chan, T., and F. W. Stanchell (2005), Subsurface hydro-mechanical (HM) impacts of glaciation: Sensitivity to transient analysis, HM coupling, fracture zone connectivity and model dimensionality, Int. J. Rock Mech. Min. Sci., 42, 828-849, doi:10.1016/j.ijrmms.2005.04.001.

Chan, T., F. W. Stanchell, T. Wallroth, J. Hernelind, and G. Boulton (2004), A finite-element study of potential coupled hydromechanical effects of glaciation on a crystalline rock mass, in Coupled Thermo-HydroMechanical-Chemical Processes in Geo-Systems. Fundamentals, Modelling, Experiments and Applications, Elsevier Geo-Engineering Book Series, vol. 2, edited by O. Stephansson et al., pp. 287-292, Elsevier, Amsterdam.

Chan, T., R. Christiansson, G. S. Boulton, L. O. Eriksson, J. Hartikainen, M. R. Jensen, D. Mas Ivars, F. W. Stanchell, P. Vistrand, and T. Wallroth (2005), DECOVALEX III/BENCHPAR PROJECTS. The thermal-hydromechanical responses to a glacial cycle and their potential implications for deep geological disposal of nuclear fuel waste in a fractured crystalline rock mass. Report of BMT3/WP4, SKI Report 2005:28, Strålsäkerhetsmyndigheten (Swedish Radiation Safety Authority), Stockholm, Sweden.

Fälth, B., H. Hökmark, and R. Munier (2010), Effects of large earthquakes on a KBS-3 repository. Evaluation of modelling results and their implications for layout and design, $S K B$ TR-08-11, Svensk Kärnbränslehantering AB (SKB), Stockholm, Sweden.

Follin, S., J. Levén, L. Hartley, P. Jackson, S. Joyce, D. Roberts, and B. Swift (2007), Hydrogeological characterisation and modelling of deformation zones and fracture domains, Forsmark modelling stage 2.2, SKB R-07-48, Svensk Kärnbränslehantering AB (SKB), Stockholm, Sweden.

Glamheden, R., A. Fredriksson, K. Röshoff, J. Karlsson, H. Hakami, and R. Christiansson (2007a), Rock mechanics Forsmark. Site descriptive modelling Forsmark stage 2.2, SKB R-07-31, Svensk Kärnbränslehantering $\mathrm{AB}$ (SKB), Stockholm, Sweden.

Glamheden, R., L. Maersk Hansen, A. Fredriksson, L. Bergkvist, I. Markström, and M. Elfström (2007b), Mechanical modelling of the Singö deformation zone. Site descriptive modelling Forsmark stage 2.1, SKB R-07-06, Svensk Kärnbränslehantering AB (SKB), Stockholm, Sweden.

Hartikainen, J., R. Kouhia, and T. Wallroth (2010), Permafrost simulations at Forsmark using a numerical 2D thermo-hydro-chemical model, SKB TR-09-17, Svensk Kärnbränslehantering AB (SKB), Stockholm, Sweden.

Haynes, W. M. (Ed. ) (2013), CRC Handbook of Chemistry and Physics, 94th Ed., (Internet Version 2014), CRC Press/Taylor and Francis, Boca Raton, FL.

Hökmark, H., B. Fälth, and T. Wallroth (2006), T-H-M couplings in rock. Overview of results of importance to the SR-Can safety assessment, SKB R-06-88, Svensk Kärnbränslehantering AB (SKB), Stockholm, Sweden.

Hökmark, H., M. Lönnqvist, and B. Fälth (2010), THM-issues in repository rock. Thermal, mechanical, thermo-mechanical and hydro-mechanical evolution of the rock at the Forsmark and Laxemar sites, SKB TR-10-23, Svensk Kärnbränslehantering AB (SKB), Stockholm, Sweden.

International Center for Numerical Methods in Engineering (2004), Code Bright. Version 2.2 Users Guide, 187 p., International Center for Numerical Methods in Engineering, Departamento de Ingeniería del Terreno, Cartográfica y Geofísica, Universidad Politécnica de Cataluna, Spain.

Kreyszig, E. (1993), Advanced Engineering Mathematics, 7th ed., 1271 p., John Wiley and Sons, Inc., New York; Chichester; Brisbane; Toronto; Singapore.

Lagerbäck, R., and M. Sundh, (2008), Early Holocene faulting and paleoseismicity in northern Sweden, Research Paper C 836, Sveriges geologiska undersökning (SGU), Sweden.

Lambeck, K. (2005), Glacial load stresses: Can existing faults or other zones of crustal weakness be reactivated during glacial cycles? in Expert Panel Elicitation of Seismicity Following Glaciation in Sweden, edited by S. Hora and M. Jensen, pp. 85-106, SSI Rapport 2005:20, Strålsäkerhetsmyndigheten (Swedish Radiation Safety Authority), Stockholm, Sweden.

Lambeck, K., A. Purcell, J. Zhao, and N.-O. Svensson (2010), The Scandinavian ice sheet: from MIS 4 to the end of the Last Glacial Maximum, Boreas, 39, 410-435, doi:10.1111/j.1502-3885.2010.00140.x.

Lemieux, J.-M., E. A. Sudicky, W. R. Peltier, and L. Tarasov (2008a), Simulating the impact of glaciations on continental groundwater flow systems: 1. Relevant processes and model formulation, J. Geophys. Res., 113, F03017, doi:10.1029/2007JF000928.

Lemieux, J.-M., E. A. Sudicky, W. R. Peltier, and L. Tarasov (2008b), Simulating the impact of glaciations on continental groundwater flow systems: 2. Model application to the Wisconsinian glaciation over the Canadian landscape, J. Geophys. Res., 113, F03018, doi:10.1029/ 2007JF000929.

Lemieux, J.-M., E. A. Sudicky, W. R. Peltier, and L. Tarasov (2008c), Dynamics of groundwater recharge and seepage over the Canadian landscape during the Wisconsinian glaciation, J. Geophys. Res., 113, F01011, doi:10.1029/2007JF000838.

Lönnqvist, M., and Hökmark, H. (2010), Assessment of potential for glacially induced hydraulic jacking at different depths, SKB R-09-35, Svensk Kärnbränslehantering AB (SKB), Stockholm, Sweden.

Lönnqvist, M., and H. Hökmark (2012), Is hydraulic jacking a threat to the long-term safety of a nuclear waste repository? in Harmonising Rock Engineering and the Environment, edited by Q. Qian and Y. Zhou, pp. 1421-1426, Taylor \& Francis Group, London, U. K.

Lund, B., P. Schmidt, and C. Hieronymus (2009), Stress evolution and fault stability during the Weichselian glacial cycle, $S K B$ TR-09-15, Svensk Kärnbränslehantering AB (SKB), Stockholm, Sweden.

Mas Ivars, D., and H. Hakami (2005), Effect of a sub-horizontal fracture zone and rock mass heterogeneity on the stress field in Forsmark area-A numerical study using 3DEC. Preliminary site description Forsmark area-Version 1.2, SKB R-05-59, Svensk Kärnbränslehantering $\mathrm{AB}$ (SKB), Stockholm, Sweden.

Moeller, C. A., D. M. Mickelson, M. P. Anderson, and C. Winguth (2007), Groundwater flow beneath Late Weichselian glacier ice in Nordfjord, Norway, J. Glaciol., 53(180), 84-90.

Neuzil, C. E. (2003), Hydromechanical coupling in geologic processes, Hydrogeol. J., 11 (1), 41-83, doi:10.1007/s10040-002-0230-8.

Neuzil, C. E. (2012), Hydromechanical effects of continental glaciation on groundwater systems, Geofluids, 12, 22-37, doi:10.1111/j.14688123.2011.00347.x

Paterson, W. S. B. (1994), The Physics of Glaciers, 3rd ed., 480 p., Elsevier Science Ltd., Oxford, U. K.

Peltier, W. R. (2004), Global glacial isostasy and the surface of the ice-age Earth: The ICE-5G (VM2) model and GRACE, Annu. Rev. Earth Planet. Sci., 32, 111-149, doi:10.1146/annurev earth.32.082503.144359.

Pollard, D. D., and A. Aydin (1988), Progress in understanding jointing over the past century, Geol. Soc. Am. Bull., 100(8), 1181-1204.

Pusch, R., L. Börgesson, and S. Knutsson (1990), Origin of silty fracture fillings in crystalline bedrock, Geol. Foeren. Stockholm Foerh., 112(3), 209-213.

Steffen, H., and P. Wu (2011), Glacial isostatic adjustment in Fennoscandia-A review of data and modeling, J. Geodyn., 52, 169-204 doi:10.1016/j.jog.2011.03.002.

Swedish Nuclear Fuel and Waste Management Company (SKB), (2005), Preliminary site description. Forsmark area-Version 1.2, SKB R-05-18, Svensk Kärnbränslehantering AB (SKB), Stockholm, Sweden.

Swedish Nuclear Fuel and Waste Management Company (SKB) (2006), Climate and climate-related issues for the safety assessment SR-Can, SKB TR-06-23, Svensk Kärnbränslehantering AB (SKB), Stockholm, Sweden.

Swedish Nuclear Fuel and Waste Management Company (SKB) (2008), Site description of Forsmark at completion of the site investigation phase. 


\section{LÖNNQVIST AND HÖKMARK: ESTIMATE OF MAXIMUM JACKING DEPTHS}

SDM-Site Forsmark, SKB TR-08-05, Svensk Kärnbränslehantering AB (SKB), Stockholm, Sweden.

Swedish Nuclear Fuel and Waste Management Company (SKB) (2010a), Climate and climate-related issues for the safety assessment SR-Site, SKB TR-10-49, Svensk Kärnbränslehantering AB (SKB), Stockholm, Sweden.

Swedish Nuclear Fuel and Waste Management Company (SKB) (2010b), Model summary report for the safety assessment SR-Site, SKB TR-10-51, Svensk Kärnbränslehantering $\mathrm{AB}$ (SKB), Stockholm, Sweden.

Swedish Nuclear Fuel and Waste Management Company (SKB) (2010c), Geosphere process report for the safety assessment SR-Site, SKB TR-1048, Svensk Kärnbränslehantering AB (SKB), Stockholm, Sweden.

Swedish Nuclear Fuel and Waste Management Company (2010d), Data report for the safety assessment SR-Site, SKB TR-10-52, Svensk Kärnbränslehantering AB (SKB), Stockholm, Sweden.

Swedish Nuclear Fuel and Waste Management Company (2011), Long-term safety for the final repository for spent nuclear fuel at Forsmark. Main report of the SR-Site project, SKB TR-11-01, Svensk Kärnbränslehantering AB (SKB), Stockholm, Sweden.

Talbot, C. J. (1990), Problems posed to a bedrock radwaste repository by gently dipping fracture zones, Geol. Foeren. Stockholm Foerh., 112(4), 355-359.

Talbot, C. J. (1999), Ice ages and nuclear waste isolation, Eng. Geol., $52(3-4), 177-192$.

Vidstrand, P., (2003), Surface and subsurface conditions in permafrost areas - a literature review, SKB TR-03-06, Svensk Kärnbränslehantering $\mathrm{AB}$ (SKB), Stockholm, Sweden.

Vidstrand, P., T. Wallroth, and L. O. Ericsson (2008), Coupled HM effects in a crystalline rock mass due to glaciation: indicative results from groundwater flow regimes and stresses from an FEM study, Bull. Eng. Geol. Environ., 67, 187-197, doi:10.1007/s10064-008-0123-8.

Walsh, R., and J. Avis, (2010), Glaciation scenario: Groundwater and radionuclide transport studies, NWMO TR-2010-09, Nuclear Waste Management Organization, Toronto, Canada. 